\title{
A cross sectional study: knowledge and practices about diarrheal diseases and ORS in the mothers of under five years children
}

\author{
Arora K.K. ${ }^{1}$, Taran S.J. ${ }^{2}$, Gupta N. ${ }^{3}$ \\ ${ }^{1}$ Dr. Kewal Kishore Arora, Assistant Professor, Paediatrics, SAMC and PG Institute, ${ }^{2}$ Dr. Shachi Jain Taran, Assistant \\ Professor, Paediatrics, MGM Medical College, Indore, MP, ${ }^{3}$ Dr. Nidhi Gupta, Junior Resident, Paediatrics, SAMC and \\ PG Institute.
}

Corresponding Author: Dr. Shachi Jain Taran, Assistant Professor, Paediatrics, MGM Medical College, Indore (M.P.) India. E-mail: shachitaran@yahoo.co.in

\begin{abstract}
Background: Diarrhoea is one of themajorkillerin under five years children worldwide. But accurate knowledge and practices about diarrheal diseases and use of ORS as an important tool in the mothers remain low. This cross sectional study was conducted to find out the level of knowledge and practices about diarrhoea and ORS in the mothers of under five children. Material and Method: This cross-sectional study was conducted in 8 randomly selected colonies of semi urban and urban area of Indore district in the year 2017. Mothers who had at least one child under five years of age with one episode of diarrhoeain the past were included in the study. Results: Most of the mothers (61.4\%) knew right description for diarrhoea. But very few mother had knowledge about causes $(23.6 \%)$ of diarrhoea. Verysmall number (26.81\%) knew about all danger signs. Majority (91.8\%) of mothers knew of ORS though only half $54.5 \%$ of them knew correct method of ORS preparation. 81.7\% mothers had some knowledge about use of home based fluid. About one third of mothers knew about Zinc tablets (34.6\%) and Rotavirus vaccine (37.3\%). 44.7\% of mother used ORS while 73.4\% used home based fluids. Post diarrheal episode only $26.36 \%$ of mothers gave extra meal to the children. Conclusion: A strong association is found between knowledge and practices regarding diarrhoea management. Hence health education should be used as a tool to promote knowledge and good practices and reduce morbidity and mortality related to acute diarrhoea.
\end{abstract}

Key words: Diarrhoea; ORS; Knowledge and Practices; Mother; Children

\section{Introduction}

Worldwide, diarrhoea remains a major public health burden. In developing countries, diarrhoea is the second leading cause of childhood morbidity and mortality. Each year, an estimated 2.5 billion cases of diarrhoea occur among children under five years of age. More than half of these cases are in Africa and South Asia. Incidence is highest in the first two years of life and declines as a child grows older. Africa and South Asia are home to more than 80 percent of child deaths due to diarrhoea [1].

Every year diarrhoea kills around 525000 children under five [2]. Although the majority of diarrheal incidents are not severe and may not require specific intervention, a large number are potentially grave. Diarrhoea is the most important public health problem

Manuscript received: $28^{\text {th }}$ January 2019

Reviewed: $4^{\text {th }}$ February 2019

Author Corrected: $10^{\text {th }}$ February 2019

Accepted for Publication: $15^{\text {th }}$ February 2019 connected to water and sanitation and can be both water borne and water-washed. Many more children could have been saved through basic interventions to improve quality of drinking water, sanitation and hygiene for diarrhoea prevention alongwith the wide spread use of a simple solution of oral rehydration salts (ORS) and zinc supplementation during incidents of acute diarrhoea. Worldwide, just over 40 per cent of children under age 5 with diarrhoea receive the recommended treatment of oral rehydration therapy and continued feeding.

Coverage of this treatment package is lowest in the Middle East and North Africa, South Asia and SubSaharan Africa (34 per cent, 37 per cent and 39 per cent, respectively). Sub-Saharan Africa and South Asia (India being in South Asia) are also the regions with the most deaths from diarrhoea. Over the observed period, progress of this important intervention has been very slow [3]. Mother's basic knowledge about diarrhoea 
prevention, management and use of ORS in diarrheal episode is very limited. According to United Nations Children's Fund (UNICEF) global data base children under age of five years with diarrhoea receiving ORS in India in 2008-2012 was just 26\% [4]. So this study was done to find out the level of knowledge and practices about diarrhoea and ORS in the mothers of under five children of our area.

\section{Material and Methods}

Place of Study- Department of Paediatrics, SAMC and PG Institute, Indore, MP.

Type of Study- Cross sectional study from November 2017 to January 2018

Sampling Method- Eight randomly selected colonies from urban and semi urban areas of Indore district, Madhya Pradesh. Convenient sampling method was employed in the study. Out of 250 mothers selected for study only 220 mothers completed questionnaire, therefore same were enrolled for the study.

Sample Collection and details of questionnaireInformed consent was taken from all the participants. Predesigned, semi structured questionnaire was

\section{Original Research Article}

prepared both in Hindi and English. Questionnaire had three sections namely demography, knowledge and practice. Same was filled by participants, investigator and team. WHO definition of diarrhoea was used.

Questions were having multiple choices as options, with some questions having more than one correct option. In multiple correct answers if more than half of choices are correctly marked then taken as good knowledge and practice.

Inclusion criteria- Mothers who had at least one child underfive years of age and had at least one episode of diarrhoea in the past six months were included in the study

Exclusion Criteria- Mothers whose children were less than 2 months or more than five years of age, or who refused to give consent or whose children had persistent diarrhoea/chronic diarrhoea were excluded from the study.

Data analysis- Data was entered in Microsoft Excel and same was used for appropriate statistical methods such as percentage and descriptive analysis.

Ethical consideration and permission- Not required.

\section{Results}

Table-1: Baseline socio-demographic variables of 220 mothers of under-five children.

\begin{tabular}{|c|c|c|}
\hline Category & Number $(n=220)$ & Percentage $(\%)$ \\
\hline \multicolumn{3}{|l|}{ Age (year) } \\
\hline$<30$ & 142 & $64.5 \%$ \\
\hline $30-35$ & 62 & $28.2 \%$ \\
\hline$>35$ & 16 & $7.3 \%$ \\
\hline \multicolumn{3}{|l|}{ Type of Family } \\
\hline Nuclear & 152 & $69.1 \%$ \\
\hline Joint & 68 & $30.9 \%$ \\
\hline \multicolumn{3}{|l|}{ Education of Mothers } \\
\hline Illiterate & 28 & $12.7 \%$ \\
\hline Middle school & 70 & $31.8 \%$ \\
\hline High school & 12 & $5.5 \%$ \\
\hline Higher secondary & 16 & $7.3 \%$ \\
\hline Graduate and above & 94 & $42.7 \%$ \\
\hline \multicolumn{3}{|l|}{ Per Capita Income } \\
\hline Up to 10000 & 66 & $30.0 \%$ \\
\hline $10001-20000$ & 50 & $22.7 \%$ \\
\hline$\geq 20001$ & 104 & $47.3 \%$ \\
\hline \multicolumn{3}{|l|}{ Source of Water } \\
\hline Narmada Water & 58 & $26.3 \%$ \\
\hline Tube well & 102 & $46.4 \%$ \\
\hline Narmada +Tube well & 60 & $27.3 \%$ \\
\hline \multicolumn{3}{|l|}{ Washroom } \\
\hline Pucca & 211 & $95.9 \%$ \\
\hline Kachha & 09 & $4.1 \%$ \\
\hline \multicolumn{3}{|c|}{ Municipal corporation drainage } \\
\hline Yes & 191 & $86.8 \%$ \\
\hline
\end{tabular}




\section{Original Research Article}

In our study, majority of mothers $(69.1 \%)$ belonged to nuclear family followed by three generation family $30.9 \%$. Majority (64.5\%) of them were in the age group of $<30$ years. Most $(42.7 \%)$ of the mothers were graduate and above. Median age of children was 31(range 3-59 months). Most (52.7\%) of the study subjects had monthly per capita income less than 20000 rupees. Majority (46.4\%) of families were using tube well water. $95.9 \%$ have proper washrooms in their houses with $86.8 \%$ have municipal corporation drainage (Table1).

Most of the mothers (61.4\%) provided right description for the diarrhoea as per WHO definition. Regarding the knowledge about causes of diarrhoea, only $23.6 \%$ of the mothers could answer multiple factors responsible for diarrhoea. Only $26.81 \%$ of the study participants identified most of the danger signs of diarrhoea, though many (214) of them knew at least one danger sign.

Table-2: Knowledge regarding diarrhoea.

\begin{tabular}{|l|c|c|}
\hline Category & Poor & Good \\
\hline About diarrhea & $(84) 38.6 \%$ & $(136) 61.4 \%$ \\
\hline Causes of diarrhea & $(168) 76.4 \%$ & $(52) 23.6 \%$ \\
\hline Danger signs of diarrhea & $(161) 73.18 \%$ & $(59) 26.81 \%$ \\
\hline
\end{tabular}

$91.8 \%$ of mothers had heard about ORS but very few mothers $(26.36 \%)$ knew that commercial ORS contains both salt and sugar. When they were questioned regarding appropriate amount of ORS to be given to the child, majority (55.9\%) of them did not knowaboutit. Half of the mothers (54.5\%) had adequate knowledge regarding technique of preparing ORS solution, butonly $17.3 \%$ of mothers knew how to store prepared ORS.Knowledge about storage of ORS was very low.And when they were questioned about hazards of not giving ORS whenever needed only $19.1 \%$ gave all the correct answer but $70.45 \%$ mothers were aware about few of hazards. Most of the mothers $(60.90 \%)$ knew from where ORS to be procured (Table 3).

\section{Table 3: Knowledge regarding ORS}

\begin{tabular}{|l|c|c|}
\hline Category & Poor & Good \\
\hline Heard about the ORS & $(18) 8.1 \%$ & $(202) 91.8 \%$ \\
\hline Component of commercial ORS & $(162) 73.4 \%$ & $(58) 26.36 \%$ \\
\hline How to prepare ORS & $(100) 45.5 \%$ & $(120) 54.5 \%$ \\
\hline Amount of ORS to be given during diarrhea & $(123) 55.9 \%$ & $(97) 44.1 \%$ \\
\hline Storage of prepared ORS solution & $(182) 82.7 \%$ & $(134) 60.90 \%$ \\
\hline From where ORS to be procured & $(86) 39.09 \%$ & $(155) 70.45 \%$ \\
\hline Awareness about hazards of not giving ORS & $(65) 29.54 \%$ & \\
\hline
\end{tabular}

Table-4: Knowledge about management of diarrhoea

\begin{tabular}{|c|c|c|}
\hline Category & Poor & Good \\
\hline Amount of fluids required to be given during diarrhea & $(74) 33.6 \%$ & $146) 66.4 \%$ \\
\hline Homemade fluids can be given during diarrhea other than ORS & (40)18.3\% & $(180) 81.7 \%$ \\
\hline Preferred diet during diarrhea & $(112) 50.9 \%$ & $(108) 49.1 \%$ \\
\hline After cessation of diarrhea how many meals to be given & $(152) 69.09 \%$ & $(68) 30.90 \%$ \\
\hline Heard about of Zinc tablets/syrup & $(144) 65.4 \%$ & $(76) 34.6 \%$ \\
\hline Heard about Rota virus vaccine, to prevent diarrhea & $(138) 62.7 \%$ & $(82) 37.3 \%$ \\
\hline Hand washing protective for diarrhea & $(18) 8.1 \%$ & $(202) 91.8 \%$ \\
\hline
\end{tabular}

When they were asked about amount of fluids required to be given during diarrhoea $66.4 \%$ knew aptly. Majority (81.7\%) knew which homemade fluids can be given during diarrhoea other than ORS. About half of mothers (49.1\%) knew which diet is preferred during diarrhoea. A very small percentage $(30.9 \%)$ of mothers knew how many extra meals are required to be given after cessation of diarrhoea. Only $34.6 \%$ of mothers knew about zinc tablets/syrup, 37.3\% of mothers knew that now Rota virus vaccine is available, to prevent diarrhoea. $91.8 \%$ of participants knew importance of hand washing for protection from diarrhoea (Table 4). 


\section{Original Research Article}

When they were asked about practices for management of childhood diarrhoea $55.5 \%$ had given extra fluids to their children during diarrhoea. $47.7 \%$ used commercial ORS in current episode or past episodes. $73.4 \%$ mothers gave home based fluids to the children during diarrhoea. Only $36.8 \%$ of mothers gave appropriate diet to their children during diarrhoea. Only $26.36 \%$ subjects had given extra meals after cessation of diarrhoea to their children. $50 \%$ mothers seek health care facility during diarrheal episode. $75.9 \%$ mothers use one or more method of maintaining hygiene to prevent diarrhea. 95.5\% mothers use some cleaning method of water at their home (Table 5). Of all mothers 82 were breast feeding their children and 56 of them accepted that feeding frequency has to be increased during diarrhoea.

Table-5: Assessment of practices by mothers for management of childhood diarrhoea.

\begin{tabular}{|l|c|c|}
\hline Practices & Poor & Good \\
\hline Extra fluids given to child during diarrhea & $(98) 44.5 \%$ & $(122) 55.5 \%$ \\
\hline Use of commercial ORS during diarrhea & $(115) 52.3 \%$ & $(105) 47.7 \%$ \\
\hline Use of home based fluids during diarrhea & $(57) 26.6 \%$ & $(162) 73.4 \%$ \\
\hline Diet given to child during diarrhea & $(139) 63.2 \%$ & $(81) 36.8 \%$ \\
\hline After cessation of diarrhea extra meals have given to child & $(162) 73.4 \%$ & $(58) 26.36 \%$ \\
\hline Practices to protect your child from diarrhea & $(53) 24.1 \%$ & $(167) 75.9 \%$ \\
\hline Any method used to clean water at home & $10(4.5) \%$ & $(210) 95.5 \%$ \\
\hline During diarrhea episode visit to hospital/healthcare facility & $(110) 50 \%$ & $(110) 50 \%$ \\
\hline
\end{tabular}

Source of knowledge for most of mothers was doctor $61.81 \%$, followed by media like television and social media. $31.36 \%$ of mothers got information from Aanganwadi or other health workers. Very small percentage (15.45\%) of mothers got information from relatives; it may be because of more number of nuclear families in our study.

\section{Discussion}

Desalegne Amare et al in their community based cross sectional study on mothers residing in North west Ethiopia also found that $86.7 \%$ of them had knowledge about diarrhea. $65.9 \%$ had knowledge about diarrhoea management and 55.1\% had good knowledge about home fluid management [5]. Olaaniyi A.A.O and Oyerinde in their study on Nigerian mothers of under two years old children found that $78.1 \%$ mothers had some knowledge about diarrhoea [6]. Results are quite similar to our study, $61.4 \%$ had knowledge about diarrhoea, $81.7 \%$ of mothers knew home based fluid and $66.4 \%$ had knowledge about fluid management of diarrhoea.

Niyaz Ahmed et al did study on 1600 infant-mother dyad of Soura, Srinagar, Kashmir and found that only $9.1 \%$ of educated mothers and $30.2 \%$ of non educated mothers were ignorant about danger signs of diarrhoea. They also found that $19.4 \%$ of mothers practiced completedietary restriction during diarrhoea [7]. In our study also 214 mothers had some knowledge of danger signs. Similarly in our study only $26.36 \%$ mother provided extra diet to their children after diarrhoea.

Atul choube, Shiv Prasad Bahal et al in their study on 972 mother/care taker in the rural area of Moradabad found that $48.3 \%$ of subjects had knowledge about
ORS. They also found that $23.75 \%$ of respondents used khichri/ dalia/ dal ka pani during diarrhoea. Regarding knowledge about the places to procure ORS, only few $18.3 \%$ ofmothershad no idea [8]. A study done on mothers residing in urban slum of Delhi by Priti Chaudhary, Saurav Basu et al, out of 125 mothers 96\% defined diarrhoeacorrectly. In their study $76 \%$ mothers used ORS while only $42 \%$ mothers were knowing about correct technique of ORS preparation [9]. DM Kadam, R Hadaye and D Pandit found that $89 \%$ of total 1022 mothers of under five children of Vasind village of Thane district of Maharashtra were aware of ORS and $70 \%$ knew how to prepare it [10].

Our results are similar to study done by Priti Chaudhary et al $91.8 \%$ had heard about ORS and 54.5\% knew correct method of preparation. Contrary to study of Atul Chaube yet al, $60.9 \%$ of our mothers knew from where ORS to be procured while $73.4 \%$ used home base fluids. This may be because we studied urban and semiurban mothers.

GR Mahor in his study found that only $40 \%$ (156) of all 400 interviewed mothers of Bhopal knew correct methods of preparation of ORS [11]. In a study on rural mothers of Morang district of Nepal by Mukhtar Ansari et al showed that $85.4 \%$ of mothers knew only two 
Original Research Article

correct steps of preparation of ORS and 91.5\% of mothers did not know correct amount of ORS to be given during diarrhoea to less than two years oldchildren [12]. In a study done on Jhalawar district of Rajasthan by Rajendra Kumar Gupta et al on 354 mothers, only 48 mothers knew that one pack should be dissolved in one litre of water. They also found that about half (163) of mothers knew about availability of ORS. Knowledge on ORS use was explained by health care provider to 156 mothersout of 240 participants [13]. In our study also Health care providers were most common source of information followed by mass media.

Manijeh Khalili et al in their study on 300 mothers visiting urban health centre in Zahedan, Iran $64.5 \%$ had moderate knowledge about diarrhoea and diet to be fed during diarrhoea. $12.7 \%$ respondents considered lethargy and $6.3 \%$ mentioned dry mouth and eyes as alarming symptom of diarrhoea. $36.5 \%$ of mothers knew that unsafe water and unclean hands as one of the factors for development of diarrhea. $64 \%$ of mothers continued breast feeding during diarrhoea and $88 \%$ used ORS. While $12 \%$ of mothers used apple juice. Similarly, 68.29\% mother increased breastfeeding during diarrhoea in our study. The source of information about different aspects of diarrhoea was physicians in $51 \%$ and health care staffs in $44.6 \%$ of participants in their study [14]. Results about source of knowledge are similar to ourstudy.

\section{Conclusion}

Knowledge of mothers regarding causes and danger signs of diarrhea is incomplete. Knowledge about storage and components of ORS was unsatisfactory. Dietary practices among the mothers during the incidents of diarrhea are also unsatisfactory. Knowledge about Zinc and Rotavirus vaccine was quite low.

A strong association was found between knowledge and practices regarding diarrhea management. Hence health education should be used as a tool to promote knowledge and good practice thereby reducing morbidity and mortality.

All mothers enrolled in the study were told about danger signs of diarrhoea, correct method of preparation, storage and administration of ORS. Other aspects of management of diarrhoea were also explained after completion of interview. Health Education was given to those who could not maintain hygiene. Important role of Zinc and Rotavirus vaccination was explained to each one of them.

\section{Contributions by authors}

(1) First author: The concept and design of the study, Statistical analysis and final approval of the version to be submitted.

(2) Second and Corresponding author: Drafting the article, search of literature, revising for important intellectual content and correspondence.

(3) Third author- Acquisition of data, search of literature and interpretation of data.

\section{Acknowledgements}

What this study adds to existing knowledge-Though knowledge about different aspect of diarrhoea management is increasing but still not complete. There are still lacunae like very few know about Zinc and Rotavirus vaccine which is provided free of cost by Madhya Pradesh government. So not only availability of resources is important but information and implementation is also important.

Funding: Nil, Conflict of interest: None initiated, Perission from IRB: Yes

\section{References}

1.United Nations Children's Fund/World Health Organisation, Diarrhoea: Why children are still dying and what can be done, 2009 Available from: https:// apps. who. int/iris/ bitstream/ handle/10665/ 44174/97 89241598415_eng.pdf [Last accessed on 2019 March 03]

2. World Health Organisation diarrhoeal disease fact sheet updated May 2017. Available from: http://www. who. int/ mediacentre /factsheets/ fs330/en/. [Last accessed on 2018 April12]

3. Diarrhoeal disease - United Nations Children's Fund UNICEF Data. Available from: https://data.unicef.org/ topic/ child-health/ diarrhoeal-disease/. [Last accessed on 2019 February]

4. Statistics | India | United Nations Children's Fund UNICEF. Available from: https:// www.unicef.org/ infobycountry/ india_statistics. html./.[Last accessed on 2019 February]

5. Amare D, Dereje B, Kassie B, Tessema M, Mullu G, et al. Maternal knowledge and practice towards diarrhoea management in under five children in Fenote Selam Town, West Gojjam Zone, Amhara Regional State, Northwest Ethiopia. J infect Dis Ther. 2014; 2 (6): 182. doi:10.4172/2332-0877.1000182. 


\section{Original Research Article}

6. Olaniya A.A.O, Oyerinde O. Knowledge of causes, management and prevention of childhood diarrhoea among nursing mothers in two selected primary health centres in Oyo State, Nigeria. World Journal of Research and Review (WJRR). 2016; 2 (3):1-5.

7. Buch NA, Hassan M, Bhat IA. Parental awareness and practices in acute diarrhea. Indian Pediatr. 1995 Jan; 32 (1):76-9.

8. Choube A, Bahal SP, Srivastava A, Sharma M. Knowledge and child care practices regarding childhood diarrhoea- A cross sectional study. Ind J Comm Health. 2014; 26(3): 285-91.

9. Chaudhary P, Basu S, Dzeyie KA, Gulla S, Khade S, et al. Knowledge, Attitude and practice of mothers regarding diarrhoeal illness in children under five years of Age: A cross sectional study in an urban slum of Delhi. India. J. Commun. Dis. 2014; 46 (3):13-21.

10. Kadam DM, Hadaye R, Pandit D. Knowledge and practices regarding oral rehydration therapy among mothers in rural area of Vasind, India. Nepal Med Coll J. 2013 Jun;15(2):110-2.

11. Mahor GR. Knowledge and attitudes of mothers regarding use of Oral Rehydration Solution in management of diarrhea. Asian journal of Biomedical and Pharmaceutical Sciences.2013;3(21):6-8.

12. Ansari M, Ibrahim MIM, Shankar PR. A survey of mothers' knowledge about childhood diarrhoea and its management among a marginalised community of Morang, Nepal. AMJ.2011;4(9):474-9 http//dx.doi.org/ AMJ.2011.821

13. Gupta RK, Nagori GL, JainDK.Study of knowledge of mothers regarding use and preparation ORS in acute diarrhoea. J of Evolution of Med and Dent Sci.2015; March09;4(20):3457-61,DOI:10.14260/jemds/2015/499

14. Khalili M, Mirshahi M, Zarghami A, Rajabnia MC, Farahmand F. Maternal knowledge and practice regarding childhood diarrhoea and diet in Zahedan, Iran. Health Scope 2013;2(1):19-24

\section{How to cite this article?}

Arora K.K, Taran S.J, Gupta N. A cross sectional study: knowledge and practices about diarrheal diseases and ORS in the mothers of under five years children. Int J Pediatr Res. 2019;6(02):58-63. doi:10.17511/ijpr.2019.i02.02 